\title{
Interaction Between NOS3 and HMOX1 on Antihypertensive Drug Responsiveness in Preeclampsia
}

\section{Interação entre os genes NOS3 e HMOX1 na resposta à terapia antihipertensiva em pré-eclâmpsia}

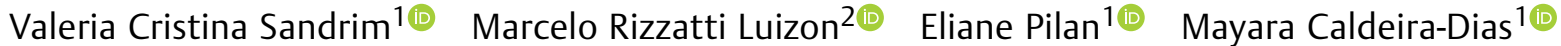

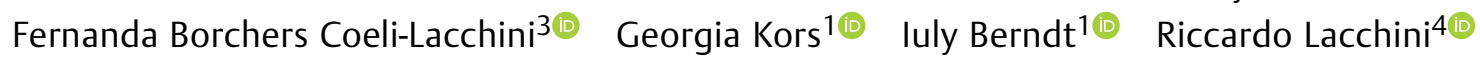

Ricardo Carvalho Cavalli ${ }^{5}$

${ }^{1}$ Department of Pharmacology, Instituto de Biociências de Botucatu,
Universidade Estadual Paulista, Botucatu, SP, Brazil
2 Department of Genetics, Ecology and Evolution, Instituto de Ciências
Biológicas, Universidade Federal de Minas Gerais, Belo Horizonte,
MG, Brazil
${ }^{3}$ Department of Internal Medicine, Faculdade de Medicina de Ribeirão
Preto, Universidade de São Paulo, São Paulo, SP, Brazil
${ }^{4}$ Department of Psychiatric Nursing and Human Sciences, Escola de
Enfermagem de Ribeirão Preto, Universidade de São Paulo, Ribeirão Preto,
SP, Brazil
${ }^{5}$ Department of Gynecology and Obstetrics, Faculdade de Medicina de
Ribeirão Preto, Universidade de São Paulo, Ribeirão Preto, SP, Brazil

Address for correspondence Valeria Cristina Sandrim, PhD, Universidade Estadual Paulista (UNESP), Departamento de Farmacologia, Instituto de Biociências de Botucatu, Distrito de Rubiao Junior, S/N, Botucatu, SP, 18618-000, Brazil (e-mail: valeria.sandrim@unesp.br).

Rev Bras Ginecol Obstet 2020;42(8):460-467.

\begin{abstract}
Objective We examined the interaction of polymorphisms in the genes heme oxygenase-1 (HMOX1) and nitric oxide synthase (NOS3) in patients with preeclampsia (PE) as well as the responsiveness to methyldopa and to total antihypertensive therapy. Methods The genes HMOX1 (rs2071746, A/T) and NOS3 (rs1799983, G/T) were genotyped using TaqMan allele discrimination assays (Applied Biosystems, Foster City, CA, USA ), and the levels of enzyme heme oxygenase-1 (HO-1) were measured using enzyme-linked immunosorbent assay (ELISA).

Results We found interactions between genotypes of the HMOX-1 and NOS3 genes and responsiveness to methyldopa and that PE genotyped as AT presents lower levels of protein HO-1 compared with AA.

\section{Keywords}

- preeclampsia

- polymorphism

- antioxidant

- nitric oxide

Resumo

Conclusion We found interactions between the HMOX-1 and NOS3 genes and responsiveness to methyldopa and that the $H M O X 1$ polymorphism affects the levels of enzyme HO-1 in responsiveness to methyldopa and to total antihypertensive therapy. These data suggest impact of the combination of these two polymorphisms on antihypertensive responsiveness in PE.

Objetivo Examinamos a interação dos polimorfismos nos genes heme oxigenase-1 (HMOX1) eóxido nítrico sintase (NOS3) em pacientes com pré-eclâmpsia (PE)bem como as capacidades de resposta à metildopa e à terapia anti-hipertensiva.
\end{abstract}

received

January 22, 2020

accepted

March 30, 2020
DOI https://doi.org/

10.1055/s-0040-1712484. ISSN 0100-7203.
Copyright $\odot 2020$ by Thieme Revinter

Publicações Ltda, Rio de Janeiro, Brazil
License terms

(c) (i) 

Palavras-chave
- pré-eclâmpsia
- polimorfismo
- antioxidante
- óxido nítrico

Métodos Os polimorfismos nos genes HMOX1 (rs2071746, A/T) e NOS3 (rs1799983, $\mathrm{G} / \mathrm{T}$ ) foram genotipados usando TaqMan allele discrimination assays (Applied Biosystems, Foster City, CA, EUA), e os níveis da enzima heme oxigenase-1 (HO-1) foram medidos por enzyme-linked immunosorbent assay (ELISA).

Resultados Foram encontradas interações entre os genótipos da HMOX-1 e NOS3 e responsividade à metildopa, e que pacientes genotipados como AT apresentam níveis mais baixos de proteína HO-1 em comparação com o genótipo AA.

Conclusão Foram encontradas interações entre os genes HMOX-1 e NOS3 e responsividade à metildopa e que o polimorfismo localizado no gene $H M O X 1$ afeta os níveis de enzima HO-1 na resposta à metildopa e à terapia anti-hipertensiva. Esses dados sugerem o impacto da combinação desses dois polimorfismos na resposta antihipertensiva na PE.

\section{Introduction}

Preeclampsia (PE) is a syndrome characterized by hypertension associated with proteinuria or other systemic signs and is considered one of the major causal factors for maternal and fetal morbidity worldwide. ${ }^{1}$ Several studies have explored the role of an unbalance between antioxidant and oxidant agents in the pathophysiology of PE, as reviewed elsewhere. ${ }^{2}$ However, despite these efforts, a small number of clinical studies have investigated the heme oxygenase-1 (HO-1), a pivotal enzyme that protects cells against oxidative stress. ${ }^{3-8}$ Heme oxygenase- 1 cleaves heme-producing bilirubin and carbon monoxide ( $\mathrm{CO}$ ), thus promoting cell protection by its antiapoptotic, antioxidant and antiinflammatory properties. Besides, in a rat model of PE a possible effect of HO-1 in regulating blood pressure levels was found. ${ }^{9,10}$

The gene code for enzyme HO-1 (HMOX1) and its $\mathrm{GT}_{\mathrm{n}}$ polymorphism were related to lower HO-1 expression and associated with non-severe late-onset PE. ${ }^{11,12}$ However, other HMOX1 polymorphisms were not examined in PE, with particular focus on single nucleotide polymorphisms (SNPs) located at the promoter of HMOX1. For example, the rs2071746 (A/T) was associated with protective factor for patients with stroke carriers of the A allele, and it was associated with higher expression of HMOX1. ${ }^{13,14}$

The nuclear factor-erythroid-derived 2-related factor-2 (Nrf2) regulates the expression of several antioxidant proteins, including HO- $1 .{ }^{15}$ Notably, the rs35652124 T $>$ C polymorphism located at the promoter of nuclear factor, erythroid 2 like 2 (NFE2L2) gene was found to modulate the forearm vasodilator response in humans. ${ }^{16}$ Moreover, the $\mathrm{C}$ allele was associated with higher diastolic blood pressure levels in Japanese women, and with high risk of cardiovascular mortality in hemodialysis patients. ${ }^{17}$ Notably, Nrf2 binds to the antioxidant response element (ARE) at the HMOX1 promoter and can regulate $\mathrm{HO}-1$ expression. ${ }^{15}$

Remarkably, gene-gene interactions have also been taken into report in pharmacogenomics studies. ${ }^{18-20}$ Therefore, it is possible that combinations of NFE2L2 and HMOX1 genotypes may be associated with the development of PE and with the responsiveness to antihypertensive therapy in patients with PE. In addition, the increased oxidative stress in PE can potentially scavenge and reduce the bioavailability of nitric oxide (NO), which may be impaired by some SNPs of the endothelial nitric oxide synthase (NOS3) gene. ${ }^{21-24}$ Notably, haplotypes formed by the combination of alleles of NOS3 polymorphisms were associated with different subgroups of response to antihypertensive therapy in $\mathrm{PE}{ }^{25}$

In the present study, we examined the distributions of NFE2L2 and HMOX1 polymorphisms in pregnant patients with PE who responded to antihypertensive therapy with those who did not respond to antihypertensive therapy. We further verified whether NFE2L2 and HMOX1 polymorphisms affect plasma HO-1 levels in these subgroups of pregnant patients with $\mathrm{PE}$. We also investigated if interactions among NFE2L2, HMOX1, and NOS3 polymorphisms were associated with $\mathrm{PE}$ and with the responsiveness to antihypertensive therapy in pregnant patients with PE.

\section{Methods}

\section{Subjects}

Approval for use of human subjects was obtained from the Institutional Review Board at the Ribeirão Preto Medical School of the Universidade de São Paulo (FMRP-USP, in the Portuguese acronym). All pregnant women were enrolled in the High Risk Ambulatory of the University Hospital at the FMRP-USP. Preeclampsia was defined in accordance to the American College of Obstetricians and Gynecologists (ACOG) as high blood pressure $(\geq 140 \mathrm{mmHg}$ systolic or $\geq 90 \mathrm{mmHg}$ diastolic at two or more measurements at least $6 \mathrm{~h}$ apart) associated with severe features in a woman after 20 weeks of gestation. ${ }^{1}$ In the present study, women with preexisting hypertension, with or without superimposed PE were not included.

Written informed consent was provided and maternal venous blood samples were collected. Genomic DNA was isolated from the cellular component of $1 \mathrm{~mL}$ of whole blood by a salting-out method and stored at $-20^{\circ} \mathrm{C}$ until use. Plasma was obtained from centrifugation of whole blood in ethylenediaminetetraacetic acid (EDTA) at 2,000 g for $10 \mathrm{~min}$ and stored at $-70^{\circ} \mathrm{C}$ until assayed. 


\section{Antihypertensive Treatment and Drug Response Evaluation}

We carefully monitored for signs and symptoms of PE in pregnant women enrolled in the present study and for fetal surveillance and laboratory tests at least once weekly. Responsiveness to therapy was evaluated through the clinical and laboratory parameters (see below) in response to the antihypertensive drugs treatment. The initial antihypertensive drug was methyldopa $(1,000-1,500 \mathrm{mg}$ per day) followed by nifedipine (40-60 mg per day) and/or hydralazine $(5-30 \mathrm{mg})$, which were added in case of lack of significant responses to methyldopa. One of the following clinical and laboratory outcomes were considered to classify a patient as nonresponsive to antihypertensive therapy:

(1) Clinical symptoms including blurred vision, persistent headache or scotomata, persistent right upper quadrant or epigastric pain;

(2) Systolic blood pressure above $140 \mathrm{mmHg}$ and diastolic blood pressure $>90 \mathrm{mmHg}$, as assessed by the blood pressure curve;

(3) Hemolysis, elevated liver enzymes, low platelet count (HELLP) syndrome; or proteinuria $>2.0 \mathrm{~g}$ per $24 \mathrm{~h}$; creatinine $>1.2 \mathrm{mg}$ per $100 \mathrm{~mL}$ or blood urea nitrogen $>30 \mathrm{mg}$ per $100 \mathrm{~mL}$; aspartate aminotransferase $>70 \mathrm{Ul}^{-1}$ and alanine aminotransferase $>60 \mathrm{Ul}^{-1}$; and

(4) Fetal hypoactivity or nonreactive fetus, as revealed by cardio tocography; intrauterine growth restriction, oligoamnio, abnormal biophysical profile score, and Doppler velocimetry abnormalities, as evaluated by ultrasound. ${ }^{25}$

In the - Supplementary Figure $\mathbf{S 1}$, we show the schematic diagram of the study workflow.

\section{Genotyping}

Genotypes for the rs35652124 polymorphism of the NFE2L2 gene were determined by polymerase chain reaction-restriction fragment length polymorphism (PCR-RFLP). The forward and reverse primers were respectively: $5^{\prime}$ CCTAGAGGAGGT CTCCGTTAG3' and 5'CTGGTACTATTTTGTGAGTACGTG3'. The PCR reaction generated product of 608 bp that was digested with BseRI (New England Biolabs, Ipswich, MA, USA) restriction enzyme. Three bands were visualized when heterozygote $680 \mathrm{bp}, 401 \mathrm{bp}$, and $268 \mathrm{bp} ; 2$ bands ( $401 \mathrm{bp}$ and $268 \mathrm{bp}$ when TT genotype), and 1 band 608 bp when CC.

Genotypes for the rs2071746 polymorphism of the HMOX1 gene were obtained using TaqMan allele discrimination assays (Applied Biosystems, Foster City, CA, USA) using real-time PCR. Probes and primers used were designed by Applied Biosystems (Assay ID: C_15869717_10 for rs2071746). Polymerase chain reactions were performed in a total volume of $12 \mu \mathrm{l}$ (3 $\mathrm{ng}$ of template DNA, $1 \times$ TaqMan genotyping master mix (Life Technologies Corporation, Grand Island, NY, USA) and $1 \times$ TaqMan allele discrimination assay). Thermal cycling was performed in standard conditions, and fluorescence was recorded by the StepOne Plus Real-Time PCR equipment (Applied Biosystems). Results were obtained with manufacturer's software. The two polymorphisms of NOS3 (rs1799983 and rs2070744) were determined using also allele discrimination assays, as described previously. ${ }^{22}$

\section{Enzyme Immunoassays of plasma HO-1}

The levels of HO-1 were measured in plasma (EDTA) using a Human total HO-1/HMOX1 kit (R \&D Systems, Minneapolis, MN, USA), according to manufacturer's instructions. Briefly, $50 \mu \mathrm{L}$ of plasma was used to each patient, and the optical density was determined at $450 \mathrm{~nm}$ using in a Synergy 4 microplate reader (BioTek, Winooski, VT, USA).

\section{Statistical Analysis}

The clinical characteristics of groups were compared by Student unpaired $t$-test, Mann-Whitney $U$-test, or $X^{2}$, as appropriate. The modulation of the genotypes for the NFE2L2 and HMOX1 polymorphisms on plasma HO-1 concentrations were compared by one-way analysis of variance (ANOVA). The distribution of genotypes was analyzed for deviation from the Hardy-Weinberg equilibrium. The differences in genotype and allele frequencies among subgroups were assessed using the $X^{2}$ test. A value of $P<0.05$ was considered statistically significant.

Multifactor dimensionality reduction (MDR) identifies interactions of genotypes for their ability to classify them into high and low-risk cells or into responsive or nonresponsive groups through cross-validation (CV) steps and permutation testing. ${ }^{26}$ We used the robust MDR approach to characterize these interaction models, which performs constructive induction using a Fisher exact test rather than a predetermined threshold and has the advantage of only considering statistically significant genotype combinations in its analysis. ${ }^{27}$ The best interaction model was the model that had the maximum testing score and CV consistency. Permutation testing was performed to determine the statistical significance of the best model. ${ }^{26,28}$

\section{Results}

- Table 1 summarizes the clinical parameters of the pregnant women enrolled in the present study. Preeclampsia was older than healthy pregnant (HP) patients $(P<0.05)$ and increased body mass index was found in PE compared with HP patients $(P<0.05)$. We found lower gestational age at delivery (GAD) and lower newborn weights in PE (all $p<0.05$ ) compared with HP patients. -Supplementary Table $\mathbf{S 1}$ shows clinical characteristics of preeclampsia women responsive or not to methyldopa or total antihypertensive therapy. Unresponsiveness (both methyldopa and total therapy) was associated with higher systolic and diastolic blood pressure, and lower GAD and newborn weighs (all $P<0.05$ ).

All the polymorphisms showed no deviation from HardyWeinberg equilibrium (all $p>0.05$, data not shown). The NFE2L2 and HMOX1 alleles and genotype frequencies distributions are similar between HP and PE patients $(P>0.05)$ ( - Table 2 ).

We, then, examined the effects of NFE2L2 and HMOX1 polymorphisms on the plasma levels of HO- 1 in the groups studied. Due to lack of available plasma, we were not able to measure the levels of $\mathrm{HO}-1$ for all subjects enrolled in the 
Table 1 Demographic characteristics of study subjects

\begin{tabular}{|c|c|c|c|}
\hline \multirow[t]{2}{*}{ Parameters } & \multirow{2}{*}{$\begin{array}{l}\text { Healthy pregnancy } \\
(n=217)\end{array}$} & \multicolumn{2}{|l|}{ Preeclampsia } \\
\hline & & $(n=181)$ & $p$-value \\
\hline Age (years) & $26 \pm 1$ & $27 \pm 1$ & 0.48 \\
\hline $\begin{array}{l}\text { Ethnicity } \\
\text { (\% White) }\end{array}$ & $152(70)$ & $129(71)$ & 0.91 \\
\hline $\begin{array}{l}\text { Current } \\
\text { smokers (\%) }\end{array}$ & $17(8)$ & $16(9)$ & 0.73 \\
\hline BMI $\left(\mathrm{Kg} / \mathrm{m}^{2}\right)$ & $21 \pm 1$ & $28 \pm 1$ & $<0.0001$ \\
\hline $\mathrm{SBP}(\mathrm{mmHg})$ & $110 \pm 1$ & $142 \pm 2$ & $<0.0001$ \\
\hline DPB (mmHg) & $70 \pm 1$ & $89 \pm 1$ & $<0.0001$ \\
\hline Primiparity (\%) & $98(45)$ & $76(42)$ & NS \\
\hline $\begin{array}{l}\text { Fasting glucose } \\
(\mathrm{mg} / \mathrm{dl})\end{array}$ & $70 \pm 2$ & $69 \pm 2$ & 0.48 \\
\hline $\begin{array}{l}\text { Hemoglobin } \\
(\mathrm{g} / \mathrm{dl})\end{array}$ & $12 \pm 1$ & $12 \pm 1$ & 1.00 \\
\hline Hematocrit (\%) & $37 \pm 5$ & $37 \pm 4$ & 1.00 \\
\hline Urea (mg/dl) & ND & $23 \pm 1$ & - \\
\hline GAD (weeks) & $40 \pm 1$ & $36 \pm 1$ & 0.0053 \\
\hline $\begin{array}{l}\text { Newborn } \\
\text { weight }(\mathrm{g})\end{array}$ & $3,359 \pm 40$ & $2,536 \pm 68$ & $<0.0001$ \\
\hline AST (IU/I) & ND & $26 \pm 17$ & - \\
\hline 24-hour $\mathrm{Pr}$ & ND & $1,402 \pm 1,628$ & - \\
\hline GAS (weeks) & $36 \pm 1$ & $34 \pm 1$ & 0.04 \\
\hline
\end{tabular}

Abbreviations: 24-hour Pr, 24-hour proteinuria; AST, aspartate transaminase; BMI, body mass index; DBP, diastolic blood pressure; GAD, gestational age at delivery; GAS, gestational age at sampling; ND, not determined; SBP, systolic blood pressure.

Values are the mean \pm SEM $^{*} p<0.05$ versus healthy pregnant group.

study. Therefore, the values are shown for $177 \mathrm{HP}$ and $116 \mathrm{PE}$ patients. We found no significant differences in the levels of HO-1 between NFE2L2 and HMOX1 genotypes nor in HP or in PE $(P>0.05)$. Genotype and allele relative frequencies for NFE2L2 and HMOX1 polymorphisms according to responsive- ness to methyldopa and to total antihypertensive therapy are shown in - Table 3. Nuclear factor, erythroid 2 like 2 polymorphism had no effects on the responses to methyldopa or to the total antihypertensive therapy. However, the TT genotype of the rs2071746 (A/T) polymorphism of HMOX1 was more frequent in the pregnant with PE nonresponsive to methyldopa group $(P=0.02)$ (-Table 3 ). However, we found no association with total antihypertensive therapy responsiveness.

Regarding the levels of HO-1, we found lower levels of HO-1 in patients with PE patients carrying the genotype AT for the HMOX1 polymorphism who were responsive to both methyldopa and to the total antihypertensive therapy compared with patients with AA genotype ( - Fig. 1) $(P<0.05)$. However, genotypes for the NFE2L2 polymorphism were not found to be associated with the levels of HO-1 in HP and PE patients, ( - Supplementary Figure $\mathbf{S 2})(P>0.05)$ neither in responsiveness and NFE2L2 polymorphism (-Supplementary Figure S3) $(P>0.05)$.

Next, we examined whether interactions among NFE2L2, HMOX1, and NOS3 polymorphisms were associated with PE and with responsiveness to methyldopa and total antihypertensive therapy. Subjects with any missing genotype data for these polymorphisms were not considered in the interaction analyses. We found a significant model of interaction among HMOX1 and NOS3 genotypes associated with responsiveness to methyldopa in pregnant patients with $\mathrm{PE}(p=0.0125)$ (-Table 4).

The combinations of genotypes are shown in - Fig. 2 . The combinations of the GG genotype for the NOS3 rs1799983 SNP with the AA and AT + TT genotypes for the HMOX1 rs2071746SNP were more frequent in the nonresponsive PE patients. Conversely, the combinations of the GT + TT genotypes for the NOS3 rs1799983 SNP with the AA and AT + TT genotypes for the HMOX1 rs2071746 $\mathrm{A}>\mathrm{T}$ SNP were more frequent in the responsive subgroup of PE patients (-Fig. 2). However, we found no interactions associated with PE or with responsiveness to total antihypertensive therapy (-Supplementary Tables $\mathbf{S 2}$ and S3) $(P>0.05)$.

Table 2 Genotype and allele relative frequencies for NFE2L2 and HMOX1 polymorphisms in the study groups

\begin{tabular}{|c|c|c|c|c|c|}
\hline Genes and polymorphisms & Genotypes and alleles & $\begin{array}{l}\text { HP } \\
\text { n (\%) }\end{array}$ & $\begin{array}{l}\mathrm{PE} \\
\mathrm{n}(\%)\end{array}$ & OR $(95 \% \mathrm{Cl})$ & $p$-value \\
\hline NFE2L2 & TT & $89(41)$ & $76(42)$ & 1.00 (reference) & - \\
\hline rs35652124 & $\mathrm{TC}$ & $100(46)$ & $81(45)$ & $0.933(0.515-1.688)$ & 0.880 \\
\hline \multirow[t]{3}{*}{$\mathrm{T}>\mathrm{C}$} & $\mathrm{CC}$ & $28(13)$ & $24(13)$ & $0.953(0.395-2.299)$ & 1.000 \\
\hline & $\mathrm{T}$ & $278(64)$ & $236(65)$ & 1.00 (reference) & - \\
\hline & C & $156(36)$ & $126(35)$ & $0.957(0.536-1.709)$ & 1.000 \\
\hline HMOX1 & AA & $56(26)$ & $49(27)$ & 1.00 (reference) & - \\
\hline rs2071746 & AT & $106(49)$ & $89(49)$ & $0.963(0.493-1.879)$ & 0.963 \\
\hline \multirow[t]{3}{*}{$\mathrm{A}>\mathrm{T}$} & TT & $54(25)$ & $43(24)$ & $0.924(0.425-2.011)$ & 0.924 \\
\hline & $A$ & $226(52)$ & $188(52)$ & 1.00 (reference) & - \\
\hline & $\mathrm{T}$ & $208(48)$ & $174(48)$ & $1.041(0.597-1.813)$ & 1.000 \\
\hline
\end{tabular}

Abbreviations: HMOX1, heme oxygenase-1; HP, healthy pregnancy; NFE2L2, nuclear factor, erythroid 2 like 2; OR, odds ratio; PE, preeclampsia. 
Table 3 Genotype and allele relative frequencies for NFE2L2 and HMOX1 polymorphisms according to responsiveness to methyldopa or to the total antihypertensive therapy

\begin{tabular}{|c|c|c|c|c|c|c|c|c|c|}
\hline & \multirow{2}{*}{$\begin{array}{l}\text { Genotype } \\
\text { or allele }\end{array}$} & \multicolumn{4}{|c|}{ Methyldopa responsiveness } & \multicolumn{4}{|c|}{ Antihypertensive therapy responsiveness } \\
\hline & & $\begin{array}{l}\mathrm{R} \\
\mathrm{n}(\%)\end{array}$ & $\begin{array}{l}\text { NR } \\
\text { n (\%) }\end{array}$ & OR $(95 \% \mathrm{Cl})$ & $p$-value & $\begin{array}{l}\mathrm{R} \\
\mathrm{n}(\%)\end{array}$ & $\begin{array}{l}\text { NR } \\
\text { n (\%) }\end{array}$ & OR $(95 \% \mathrm{Cl})$ & $p$-value \\
\hline NFE2L2 & TT & $27(48)$ & $50(40)$ & 1.00 (reference) & - & $48(47)$ & $30(37)$ & 1.00 (reference) & - \\
\hline rs35652124 & $\mathrm{TC}$ & $23(41)$ & $58(47)$ & $1.376(0.760-2.489)$ & 0.365 & $43(42)$ & $38(48)$ & $1.452(0.798-2.639)$ & 0.229 \\
\hline \multirow[t]{3}{*}{$\mathrm{T}>\mathrm{C}$} & CC & $6(11)$ & $16(13)$ & $1.418(0.573-3.510)$ & 0.495 & $11(11)$ & $11(15)$ & $1.7329(0.712-4.216)$ & 0.265 \\
\hline & $\mathrm{T}$ & $76(68)$ & $159(64)$ & 1.00 (reference) & - & $139(68)$ & $96(61)$ & 1.00 (reference) & - \\
\hline & C & $36(32)$ & $92(36)$ & $1.195(0.665-2.148)$ & 0.654 & $67(32)$ & $61(39)$ & $1.359(0.759-2.430)$ & 0.375 \\
\hline HMOX1 & AA & $15(28)$ & $33(26)$ & 1.00 (reference) & - & $29(28)$ & $20(24)$ & 1.00 (reference) & - \\
\hline rs2071746 & AT & $34(61)$ & $55(44)$ & $0.776(0.401-1.503)$ & 0.502 & $53(52)$ & $36(45)$ & $1.010(0.513-1.985)$ & 1.000 \\
\hline \multirow[t]{3}{*}{$A>T$} & TT & $6(11)$ & $38(30)$ & $2.937(1.226-7.033)$ & 0.020 & $20(20)$ & $25(31)$ & $1.808(0.826-3.958)$ & 0.168 \\
\hline & $A$ & $65(58)$ & $119(47)$ & 1.00 (reference) & - & $108(54)$ & $76(47)$ & 1.00 (reference) & - \\
\hline & $\mathrm{T}$ & $47(42)$ & $131(53)$ & $1.555(0.890-2.722)$ & 0.156 & $92(46)$ & $85(53)$ & $1.324(0.759-2.308)$ & 0.396 \\
\hline
\end{tabular}

Abbreviations: $\mathrm{Cl}$, confidence interval; HMOX1, heme oxygenase 1; NFE2L2, nuclear factor, erythroid 2 like 2; NR, non-responsive; OR, odds ratio; $\mathrm{R}$, responsive.

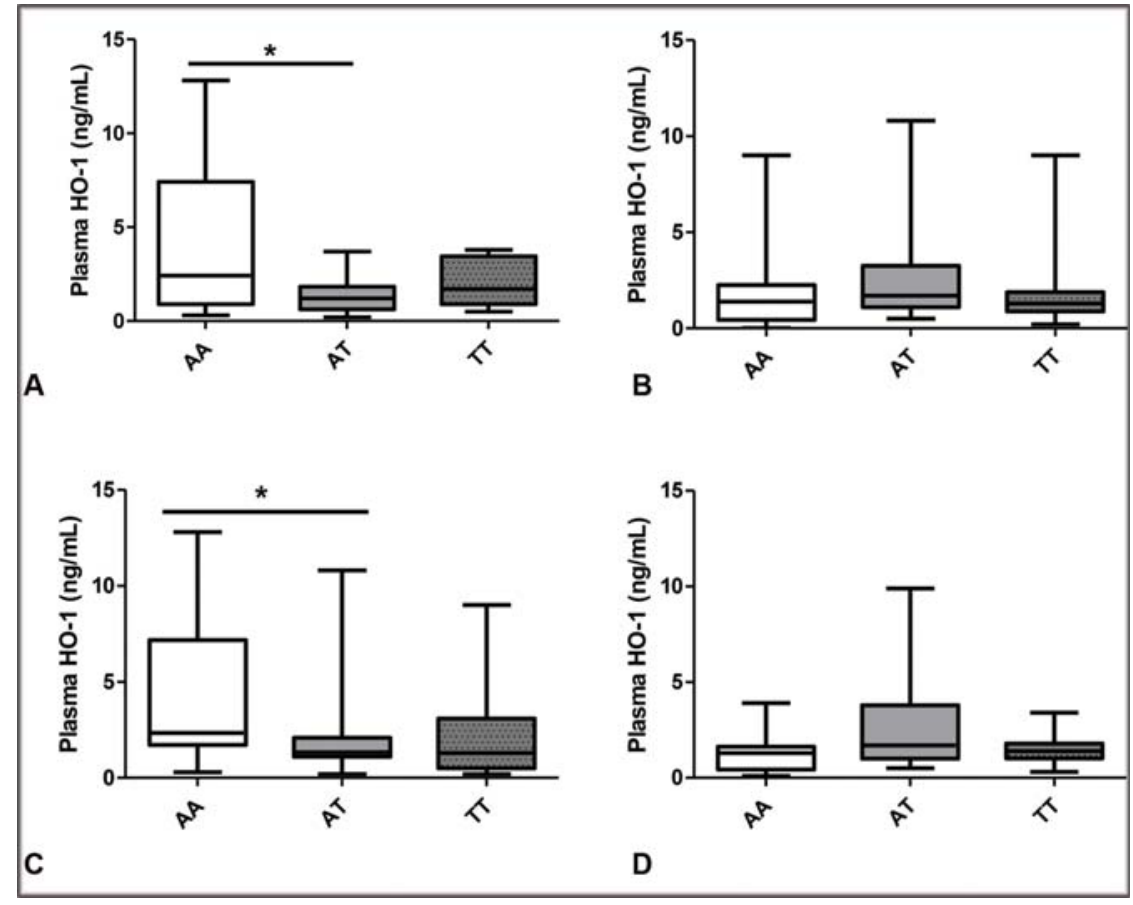

Fig. 1 Plasma HO-1 levels in patients with preeclampsia grouped according to the genotypes for the HMOX 1 polymorphism and responsiveness to methyldopa (responsive $\mathbf{A}$ and nonresponsive $\mathbf{B}$ ) or total antihypertensive therapy (responsive $\mathbf{C}$ and nonresponsive $\mathrm{D}$ ). The bars show the boxplot indicates median [min - max]. ${ }^{*} P<0.05$ versus the AA genotype.

Table 4 Robust multifactor dimensionality reduction interaction model among the NFE2L2, HMOX1, and NOS3 polymorphisms in preeclampsia patients classified as nonresponsive and responsive to methyldopa

\begin{tabular}{|c|c|c|c|c|}
\hline Interaction models & Training score & Testing score & CVC & $p$-value \\
\hline NOS3rs1799983 & 0.7220 & 0.7220 & $10 / 10$ & - \\
\hline HMOX1 rs2071746; NOS3 rs1799983 & 0.7186 & 0.6898 & $7 / 10$ & $0.0125^{*}$ \\
\hline
\end{tabular}


Table 4 (Continued)

\begin{tabular}{|c|c|c|c|c|}
\hline Interaction models & Training score & Testing score & CVC & $p$-value \\
\hline HMOX1 rs2071746; NOS3 rs2070744; NOS3 rs1799983 & 0.7183 & 0.6263 & $6 / 10$ & 0.1565 \\
\hline NFE2L2 rs35652124; HMOX1 rs2071746; NOS3 rs2070744; NOS3 rs1799983 & 0.5799 & 0.4572 & $10 / 10$ & 0.9420 \\
\hline
\end{tabular}

Abbreviations: CVC, cross-validation consistency; GH, gestational hypertension; HMOX1, heme oxygenase-1; HP, healthy pregnancy; MDR, multifactor dimensionality reduction; NFE2L2, nuclear factor, erythroid 2 Like 2; NOS3, nitric oxide synthase 3; PE, preeclampsia.

${ }^{*} P$-value after 1,000 permutations.

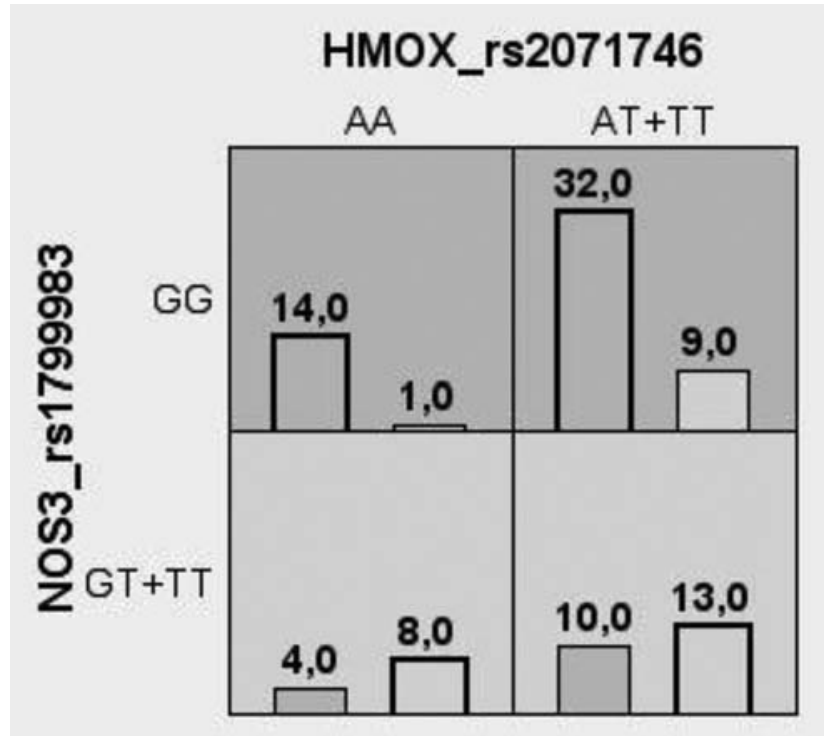

Fig. 2 The best robust multifactor dimensionality reduction model of interaction between genotypes for the HMOX1 rs2071746 A > T and NOS3 rs1799983 G > T (Glu298Asp) polymorphisms when comparing preeclampsia patients classified according to responsiveness to methyldopa. The distributions of nonresponsive (left bars) and responsive (right bars) patients are illustrated for each combination of multilocus genotypes. The dark gray cells are labeled as high risk or nonresponsive, light gray cells are labeled as low risk or responsive, and white cells are labeled as unknown.

\section{Discussion}

The present study was the first to examine whether interactions among genes NFE2L2, HMOX1, and NOS3 are associated with PE, and with the responsiveness to methyldopa and total antihypertensive therapy in PE. Moreover, this study was the first to evaluate the effect of NFE2L2 and HMOX1 polymorphisms on the plasma levels of HO-1 in both in HP and PE patients and with the responsive and nonresponsive groups to methyldopa and antihypertensive therapy in PE patients. Our main novel findings are (1) the TT genotype of the HMOX1 rs2071746 polymorphism is associated with the patients with PE who were nonresponsive to methyldopa; (2) the rs2071746 polymorphism affects the plasma levels of HO-1 in the methyldopa and total antihypertensive responsive group of patients with PE, and (3) significant interactions between genotypes of the HMOX1 rs2071746 and NOS3 rs1799983 polymorphism were found to be associated with responsiveness to methyldopa in PE patients.

To our knowledge, only two studies have compared the circulating levels of HO-1 in PE and HP patients. One study found higher levels of HO- 1 in PE patients. ${ }^{4}$ However, we found no significant differences when we compared HP with PE patients. Our findings are supported by another study showing no differences in the serum levels of HO-1 between HP and mild PE women. Moreover, we found no effects of genotypes for NFE2L2 and HMOX1 polymorphisms on the plasma levels of HO-1 in PE or in HP patients. ${ }^{3}$ While no study has examined whether NFE2L2 and HMOX1 polymorphisms affect the responsiveness to methyldopa and total antihypertensive therapy in PE, we have also examined the effects of these polymorphisms on the plasma levels of HO-1 in PE patients. We found that the AT genotype for the rs2071746 polymorphism of HMOX1 is associated with lower plasma levels of HO1 in PE patients responsive to methyldopa and total antihypertensive therapy in PE patients. It is probable that we cannot find lower levels of HO-1 in patients with TT genotype due of the lower number of subjects carrying this genotype. However, no functional study was performed to show how the rs2071746 HMOX1 polymorphism affects HMOX1 expression.

We found significant interactions among HMOX1 and NOS3 polymorphisms associated with responsiveness to methyldopa in PE patients. Although the single-analysis found that the HMOX1 polymorphism was more frequent in the subgroup of PE patients who are nonresponsive to methyldopa, the combinations with the genotypes for the NOS3 rs1799983 SNP were associated with both the responsive and the nonresponsive subgroup of PE patients. These findings suggest that specific combinations of genotypes of the HMOX1 and NOS3 SNPs may affect the responses to antihypertensive therapy using methyldopa in PE patients.

There is mounting evidence that suggest a relationship between NO and HO-1 pathways. It seems to be a crossregulation in which NO can be directly involved in the modulation of HO-1 expression, and, likewise, HO-1 expression may increase NO bioavailability. ${ }^{29,30}$ Different substances that release NO were shown to significantly upregulate HO-1 mRNA and protein expression, as well as the enzyme activity in different tissues. ${ }^{31-33}$ In addition, increased endogenous NO derived from stimulated iNOS appears to enhance $\mathrm{HO}-1$ protein expression, which was suppressed in the presence of NOS inhibitors. $^{34-36}$ These findings show that endogenously 
generated NO can trigger the expression of HO-1. Nevertheless, the exact molecular mechanisms involving both exogenous and endogenously formed NO (or NO-related species) and how they activate the HMOX1 gene are not clear. Conversely, there may be other possible mechanisms for vascular NO regulation via HO-1 and its products, as reviewed elsewhere. ${ }^{30}$

One possibility is through the modulation of eNOS expression and activity. When the concentrations of L-arginine or $\mathrm{BH}_{4}$ are low, eNOS activity can be altered due to eNOS uncoupling, which can generate superoxide $\left(\mathrm{O}_{2}^{-}\right)$. Superoxide can react spontaneously with $\mathrm{NO}$, leading to the formation of peroxynitrite $\left(\mathrm{ONOO}^{-}\right)$, which, in turn, decreases NO bioavailability. ${ }^{37}$ Increased $\mathrm{HO}-1$ expression via pharmacological Nrf2 activation was shown to down-regulate eNOS expression, thereby contributing to eNOS coupling by ensuring stoichiometric balance between $\mathrm{BH}_{4}$ and eNOS. ${ }^{38}$ Other possible mechanism for the regulation via $\mathrm{HO}-1$ and its products is reducing $\mathrm{NO}$ inactivation by inhibiting the sources of $\mathrm{O}_{2}^{-}$production, such as $\mathrm{NADPH}$ oxidase, or up-regulating antioxidant enzymes, such as superoxide dismutase (SOD) and catalase. ${ }^{39-45}$ Finally, other possible mechanism is compensating the loss of NO by CO effects. Since $\mathrm{CO}$ and NO have similar properties, as $\mathrm{CO}$ has been shown to reduce vasoconstriction and stimulate vascular relaxation by soluble guanylate cyclase (sGC) and cyclic guanosine monophosphate (cGMP). ${ }^{33,46}$ In conclusion, although there are several findings evidencing the relationship between NO and HO1 , further studies need to be performed to fully elucidate the potential mechanisms underlying this cross-regulation.

\section{Conclusion}

In conclusion, the rs2071746 polymorphism of HMOX1 affects the plasma levels of HO-1 in patients with PE who are responsive to methyldopa and total antihypertensive therapy, and we found significant interactions between the genotypes of HMOX-1 rs2071746 and NOS3 rs1799983 polymorphisms associated with responsiveness to methyldopa. Taken together, our findings suggest that the HMOX1 and NOS3 polymorphisms may affect the levels of HO-1 and NO mainly in PE patients who are responsive to methyldopa.

\section{Contributions}

Sandrim VC participated in the genetic analysis, study design, was involved in the statistical analyses and in the manuscript writing. Pilan E., Caldeira-Dias M., Coeli-Lacchini F. B., Kors G., Berndt I., Lacchini R., Luizon M. R. participated in the genetic analysis, and manuscript writing and revision. Cavalli R. C. participated in the study by recruiting the patients, collecting the samples, and revising the manuscript.

\section{Conflict of Interests}

The authors have no conflict of interests to declare.

\section{Acknowledgments}

Financial disclosure: This study was funded by São Paulo Research Foundation (FAPESP [in the Portuguese acronym], grant \#2015/20461-8), Coordination for the
Improvement of Higher Education Personnel (CAPES) and The Brazilian National Council for Scientific and Technological Development (CNPq [in the Portuguese acronym], grant \#2014-5/305587).

\section{References}

1 American College of Obstetricians and Gynecologists; Task Force on Hypertension in Pregnancy. Hypertension in pregnancy. Report of the American College of Obstetricians and Gynecologists' Task Force on Hypertension in Pregnancy. Obstet Gynecol. 2013;122(05): 1122-1131. Doi: 10.1097/01.AOG.0000437382.03963.88

2 Sánchez-Aranguren LC, Prada CE, Riaño-Medina CE, Lopez M. Endothelial dysfunction and preeclampsia: role of oxidative stress. Front Physiol. 2014;5:372. Doi: 10.3389/fphys.2014.00372

3 Vitoratos N, Papakonstantinou K, Deliveliotou A, Economou E, Panoulis C, Hassiakos D, Creatsas GK. Antepartum and postpartum serum heme oxygenase-1 levels in preeclamptic and normotensive pregnant women. In Vivo. 2011;25(03):445-450

4 Eide IP, Isaksen CV, Salvesen KA, Langaas M, Schønberg SA, Austgulen R. Decidual expression and maternal serum levels of heme oxygenase 1 are increased in pre-eclampsia. Acta Obstet Gynecol Scand. 2008;87(03):272-279. Doi: 10.1080/00016340701763015

5 Tong S, Kaitu'u-Lino TJ, Onda K, Beard S, Hastie R, Binder NK, et al. Heme oxygenase- 1 is not decreased in preeclamptic placenta and does not negatively regulate placental soluble fms-like tyrosine kinase-1 or soluble endoglin secretion. Hypertension. 2015;66 (05):1073-1081. Doi: 10.1161/HYPERTENSIONAHA.115.05847

6 Ehsanipoor RM, Fortson W, Fitzmaurice LE, Liao WX, Wing DA, Chen DB, Chan K. Nitric oxide and carbon monoxide production and metabolism in preeclampsia. Reprod Sci. 2013;20(05): 542-548. Doi: 10.1177/1933719112459231

7 Farina A, Sekizawa A, De Sanctis P, Purwosunu Y, Okai T, Cha DH, et al. Gene expression in chorionic villous samples at 11 weeks' gestation from women destined to develop preeclampsia. Prenat Diagn. 2008;28(10):956-961. Doi: 10.1002/pd.2109

8 McLaughlin BE, Lash GE, Smith GN, Marks GS, Nakatsu K, Graham $\mathrm{CH}$, Brien JF. Heme oxygenase expression in selected regions of term human placenta. Exp Biol Med (Maywood). 2003;228(05): 564-567. Doi: 10.1177/15353702-0322805-28

9 Ahmed A. Molecular mechanisms and therapeutic implications of the carbon monoxide/hmox1 and the hydrogen sulfide/CSE pathways in the prevention of pre-eclampsia and fetal growth restriction. Pregnancy Hypertens. 2014;4(03):243-244. Doi: 10.1016/j. preghy.2014.04.013

10 George EM, Cockrell K, Aranay M, Csongradi E, Stec DE, Granger JP. Induction of heme oxygenase 1 attenuates placental ischemiainduced hypertension. Hypertension. 2011;57(05):941-948. Doi: 10.1161/HYPERTENSIONAHA.111.169755

11 Chen YH, Lin SJ, Lin MW, Tsai HL, Kuo SS, Chen JW, et al. Microsatellite polymorphism in promoter of heme oxygenase-1 gene is associated with susceptibility to coronary artery disease in type 2 diabetic patients. Hum Genet. 2002;111(01):1-8. Doi: 10.1007/s00439-002-0769-4

12 Kaartokallio T, Klemetti MM, Timonen A, Uotila J, Heinonen S, Kajantie E, et al. Microsatellite polymorphism in the heme oxygenase-1 promoter is associated with nonsevere and late-onset preeclampsia. Hypertension. 2014;64(01):172-177. Doi: 10.1161/ HYPERTENSIONAHA.114.03337

13 Cao L, Zhang Z, Cai B, Bai W, Zhang Y, Sun W, et al. Association of heme oxygenase-1 gene rs2071746 polymorphism with vascular outcomes in patients with atherosclerotic stroke. J Neurol Sci. 2014;344(1-2):154-157. Doi: 10.1016/j.jns.2014.06.046

14 Ono K, Goto Y, Takagi S, Baba S, Tago N, Nonogi H, Iwai N. A promoter variant of the heme oxygenase-1 gene may reduce the incidence of ischemic heart disease in Japanese. Atherosclerosis. 2004;173(02): 315-319. Doi: 10.1016/j.atherosclerosis.2003.11.021 
15 Singh S, Vrishni S, Singh BK, Rahman I, Kakkar P. Nrf2-ARE stress response mechanism: a control point in oxidative stress-mediated dysfunctions and chronic inflammatory diseases. Free Radic Res. 2010;44(11):1267-1288. Doi: 10.3109/10715762.2010.507670

16 Marczak ED, Marzec J, Zeldin DC, Kleeberger SR, Brown NJ, Pretorius $M$, Lee CR. Polymorphisms in the transcription factor NRF2 and forearm vasodilator responses in humans. Pharmacogenet Genomics. 2012;22(08):620-628. Doi: 10.1097/FPC.0b013e32835516e5

17 Shimoyama Y, Mitsuda Y, Tsuruta Y, Hamajima N, Niwa T. Polymorphism of Nrf2, an antioxidative gene, is associated with blood pressure and cardiovascular mortality in hemodialysis patients. Int J Med Sci. 2014;11(07):726-731. Doi: 10.7150/ijms.8590

18 Pander J, Wessels JA, Mathijssen RH, Gelderblom H, Guchelaar HJ. Pharmacogenetics of tomorrow: the $1+1=3$ principle. Pharmacogenomics. 2010;11(07):1011-1017. Doi: 10.2217/pgs.10.87

19 Luizon MR, Palei ACT, Belo VA, Amaral LM, Lacchini R, Duarte G, et al. Gene-gene interactions in the NAMPT pathway, plasma visfatin/NAMPT levels, and antihypertensive therapy responsiveness in hypertensive disorders of pregnancy. Pharmacogenomics J. 2017;17(05):427-434. Doi: 10.1038/tpj.2016.35

20 Luizon MR, Pereira DA, Sandrim VC. Pharmacogenomics of hypertension and preeclampsia: focus on gene-gene interactions. Front Pharmacol. 2018;9:168. Doi: 10.3389/fphar.2018.00168

21 Sandrim VC, Palei ACT, Metzger IF, Gomes VA, Cavalli RC, TanusSantos JE. Nitric oxide formation is inversely related to serum levels of antiangiogenic factors soluble fms-like tyrosine kinase- 1 and soluble endogline in preeclampsia. Hypertension. 2008;52 (02):402-407. Doi: 10.1161/HYPERTENSIONAHA.108.115006

22 Muniz L, Luizon MR, Palei ACT, Lacchini R, Duarte G, Cavalli RC, et al. eNOS tag SNP haplotypes in hypertensive disorders of pregnancy. DNA Cell Biol. 2012;31(12):1665-1670. Doi: 10.1089/dna.2012.1768

23 de Miranda JA, Lacchini R, Belo VA, Lanna CM, Sertorio JT, Luizon MR, Tanus-Santos JE. The effects of endothelial nitric oxide synthase tagSNPs on nitrite levels and risk of hypertension and obesity in children and adolescents. J Hum Hypertens. 2015;29 (02):109-114. Doi: 10.1038/jhh.2014.48

24 Metzger IF, Luizon MR, Lacchini R, Ishizawa MH, Tanus-Santos JE. Effects of endothelial nitric oxide synthase tagSNPs haplotypes on nitrite levels in black subjects. Nitric Oxide. 2013;28:33-38. Doi: 10.1016/j.niox.2012.10.002

25 Sandrim VC, Palei ACT, Luizon MR, Izidoro-Toledo TC, Cavalli RC, Tanus-Santos JE. eNOS haplotypes affect the responsiveness to antihypertensive therapy in preeclampsia but not in gestational hypertension. Pharmacogenomics J. 2010;10(01):40-45. Doi: 10.1038/tpj.2009.38

26 Motsinger AA, Ritchie MD. Multifactor dimensionality reduction: an analysis strategy for modelling and detecting gene-gene interactions in human genetics and pharmacogenomics studies. Hum Genomics. 2006;2(05):318-328. Doi: 10.1186/1479-7364-2-5-318

27 Gui J, Andrew AS, Andrews P, Nelson HM, Kelsey KT, Karagas MR, Moore JH. A robust multifactor dimensionality reduction method for detecting gene-gene interactions with application to the genetic analysis of bladder cancer susceptibility. Ann Hum Genet. 2011;75(01):20-28. Doi: 10.1111/j.1469-1809.2010.00624.x

28 Luizon MR, Palei ACT, Sandrim VC, et al. Tissue inhibitor of matrix metalloproteinase-1 polymorphism, plasma TIMP-1 levels, and antihypertensive therapy responsiveness in hypertensive disorders of pregnancy. Pharmacogenomics J. 2014;14(06):535-541. Doi: $10.1038 /$ tpj.2014.26

29 Motterlini R, Green CJ, Foresti R. Regulation of heme oxygenase-1 by redox signals involving nitric oxide. Antioxid Redox Signal. 2002;4(04):615-624. Doi: 10.1089/15230860260220111

30 Pae HO, Son Y, Kim NH, Jeong HJ, Chang KC, Chung HT. Role of heme oxygenase in preserving vascular bioactive NO. Nitric Oxide. 2010;23(04):251-257. Doi: 10.1016/j.niox.2010.08.002

31 Foresti R, Motterlini R. The heme oxygenase pathway and its interaction with nitric oxide in the control of cellular homeosta- sis. Free Radic Res. 1999;31(06):459-475. Doi: 10.1080/ 10715769900301031

32 Durante W, Kroll MH, Christodoulides N, Peyton KJ, Schafer AI. Nitric oxide induces heme oxygenase- 1 gene expression and carbon monoxide production in vascular smooth muscle cells. Circ Res. 1997;80(04):557-564. Doi: 10.1161/01.res.80.4.557

33 Sammut IA, Foresti R, Clark JE, Exon DJ, Vesely MJ, Sarathchandra P, et al. Carbon monoxide is a major contributor to the regulation of vascular tone in aortas expressing high levels of haeme oxygenase- $1 . \mathrm{Br} \mathrm{J}$ Pharmacol. 1998;125(07):1437-1444. Doi: 10.1038/sj.bjp.0702212

34 Kitamura Y, Furukawa M, Matsuoka Y, Tooyama I, Kimura H, Nomura $Y$, Taniguchi $T$. In vitro and in vivo induction of heme oxygenase-1 in rat glial cells: possible involvement of nitric oxide production from inducible nitric oxide synthase. Glia. 1998;22 (02):138-148. Doi: 10.1002/(SICI)1098-1136(199802)22:2<138: AID-GLIA5 > 3.0.CO;2-3

35 Immenschuh S, Tan M, Ramadori G. Nitric oxide mediates the lipopolysaccharide dependent upregulation of the heme oxygenase-1 gene expression in cultured rat Kupffer cells. J Hepatol. 1999;30(01):61-69. Doi: 10.1016/s0168-8278(99)80008-7

36 Datta PK, Lianos EA. Nitric oxide induces heme oxygenase-1 gene expression in mesangial cells. Kidney Int. 1999;55(05):1734-1739. Doi: 10.1046/j.1523-1755.1999.00429.x

37 Schulz E, Jansen T, Wenzel P, Daiber A, Münzel T. Nitric oxide, tetrahydrobiopterin, oxidative stress, and endothelial dysfunction in hypertension. Antioxid Redox Signal. 2008;10(06):1115-1126. Doi: 10.1089/ars.2007.1989

38 Heiss EH, Schachner D, Werner ER, Dirsch VM. Active NF-E2related factor (Nrf2) contributes to keep endothelial NO synthase (eNOS) in the coupled state: role of reactive oxygen species (ROS), eNOS, and heme oxygenase (HO-1) levels. J Biol Chem. 2009;284 (46):31579-31586. Doi: 10.1074/jbc.M109.009175

39 Sue YM, Cheng CF, Chang CC, Chou Y, Chen CH, Juan SH. Antioxidation and anti-inflammation by haem oxygenase-1 contribute to protection by tetramethylpyrazine against gentamicininduced apoptosis in murine renal tubular cells. Nephrol Dial Transplant. 2009;24(03):769-777. Doi: 10.1093/ndt/gfn545

40 Datla SR, Dusting GJ, Mori TA, Taylor CJ, Croft KD, Jiang F. Induction of heme oxygenase- 1 in vivo suppresses NADPH oxidase derived oxidative stress. Hypertension. 2007;50(04): 636-642. Doi: 10.1161/HYPERTENSIONAHA.107.092296

41 Jiang F, Roberts SJ, Datla Sr, Dusting GJ. NO modulates NADPH oxidase function via heme oxygenase- 1 in human endothelial cells. Hypertension. 2006;48(05):950-957. Doi: 10.1161/01. HYP.0000242336.58387.1f

42 Wang X, Wang Y, Kim HP, Nakahira K, Ryter SW, Choi AMK. Carbon monoxide protects against hyperoxia-induced endothelial cell apoptosis by inhibiting reactive oxygen species formation. J Biol Chem. 2007;282(03):1718-1726. Doi: 10.1074/jbc.M607610200

43 Turkseven S, Kruger A, Mingone CJ, Kaminski P, Inaba M, Rodella LF, et al. Antioxidant mechanism of heme oxygenase-1 involves an increase in superoxide dismutase and catalase in experimental diabetes. Am J Physiol Heart Circ Physiol. 2005;289(02):H701-H707. Doi: 10.1152/ajpheart.00024.2005

44 Kruger AL, Peterson S, Turkseven S, Kaminski PM, Zhang FF, Quan S, et al. D-4F induces heme oxygenase- 1 and extracellular superoxide dismutase, decreases endothelial cell sloughing, and improves vascular reactivity in rat model of diabetes. Circulation. 2005;111 (23):3126-3134. Doi: 10.1161/CIRCULATIONAHA.104.517102

45 Ahmad M, Zhao X, Kelly MR, Kandhi S, Perez O, Abraham NG, Wolin MS. Heme oxygenase-1 induction modulates hypoxic pulmonary vasoconstriction through upregulation of ecSOD. Am J Physiol Heart Circ Physiol. 2009;297(04):H1453-H1461. Doi: 10.1152/ajpheart.00315.2009

46 Zhang F, Kaide JI, Rodriguez-Mulero F, Abraham NG, Nasjletti A. Vasoregulatory function of the heme-heme oxygenase-carbon monoxide system. Am J Hypertens. 2001;14(6 Pt 2):62S-67S. Doi: 10.1016/s0895-7061(01)02071-4 